\title{
IMPORTÂNCIA DOS ASPECTOS SOCIOAMBIENTAIS PARA O PLANEJAMENTO AMBIENTAL NA/DA BACIA DO CÓRREGO OLHOS D’ÁGUA, UBERLÂNDIA-MG
}

\author{
Fernanda Oliveira Borges ${ }^{(a)}$, Carlos Roberto Bernardes de Souza Júnior ${ }^{(b)}$ \\ (a) Instituto de Geografia, Universidade Federal de Uberlândia, fborges242@gmail.com \\ (b) Instituto de Estudos Socio-Ambientais, Universidade Federal de Goiás, carlosroberto2094@gmail.com

\section{EIXO: BACIAS HIDROGRÁFICAS E RECURSOS HÍDRICOS: ANÁLISE, PLANEJAMENTO E GESTÃO}

\begin{abstract}
Resumo
Usar a delimitação de bacias hidrográficas como unidade de planejamento ambiental possui uma série de benefícios metodológicos, já que esta delimitação facilita a análise de diversos fatores ambientais que implicam em uma elaboração mais próxima das características reais do ambiente e na melhoria/resolução dos problemas ambientais. Entretanto, o planejamento ambiental não deve focarse somente nos atributos do meio físico, devendo abranger também, com igual importância, os aspectos socioambientais. A ocupação das terras pelo homem se dá a partir de um curso hídrico, em função da disponibilidade de recursos para subsistência, bem como para transporte, assim, vale destacar a importância de um recorte hidrográfico como unidade de análise dos agentes sociais e suas relações com o meio. A partir disso, alcança-se os objetivos deste trabalho ao avaliar os aspectos socioambientais da bacia do córrego Olhos D'Água, entendendo sua importância, uma vez que os agentes sociais usufruem e se interagem com o ambiente.
\end{abstract}

Palavras chave: Bacias Hidrográficas. Fatores Ambientais. Agentes Sociais. Ambiente.

\section{Introdução}

A temática abordada no presente trabalho constitui-se como importante tópico de discussão no que tange o planejamento ambiental, principalmente em áreas com significativo grau de modificações antrópicas. Utilizar a divisão limítrofe das bacias hidrográficas no planejamento ambiental apresenta consideráveis benefícios metodológicos, já que esta delimitação facilita a análise de diversos fatores ambientais que implicam em uma elaboração mais próxima das características reais do ambiente e na melhoria/resolução dos problemas ambientais e sociais.

Entretanto, o planejamento ambiental não deve focar-se somente nos atributos do meio físico, há necessidade de abranger também, com igual importância, os aspectos socioambientais. Afinal, esses dificilmente estão limitados na área da bacia hidrográfica, mas nos limites municipais, distritais, etc.

A escolha da bacia hidrográfica do córrego Olhos D'água para a discussão dessa análise deu-se pelo fato dessa região ser integrante do cinturão verde do município de Uberlândia. Além disso, a mesma apresenta 
diversos conflitos relacionados à disponibilidade hídrica e configura-se como área de grande importância para a verificação de um planejamento ambiental eficaz que resulte em um possível manejo adequado dos recursos hídricos.

Dessa forma, o trabalho justifica-se pela importância da discussão da bacia hidrográfica como unidade do planejamento ambiental, juntamente com a análise conjunta da interação dos elementos que as compõem, de modo a identificar os efeitos da ação antrópica na Bacia do córrego Olhos D’água - Uberlândia (MG), assim como as representações e as relações da comunidade com tal córrego e os possíveis panoramas socioambientais para a análise da bacia em questão.

\section{O lugar e seus agentes sociais: dinâmicas e relações}

\subsection{Relações no/do lugar}

Apesar da Comunidade Rural dos Olhos D’Água estar localizada fora da área delimitada para estudo, a pesquisa sobre a mesma é necessária, uma vez que a água do córrego é utilizada para irrigação e uso diário, por meio do rego d'água construído para satisfazer tais necessidades. A considerar também que a partir do momento em que uma área delimitada para estudo parte de uma bacia hidrográfica e, esta última estando sujeita a conflitos, uso e manutenção, sua influência vai além de seu território. Afinal,

para a definir a área de estudo, deve-se partir de considerações sobre a complexidade local, a abrangência e o núcleo dos principais problemas regionais, as escalas necessárias para avaliar as questões ambientais e o tamanho das unidades territoriais envolvidas (SANTOS, 2004, p. 40).

E assim entender as relações existentes no/do lugar, para possibilitar ações de planejamento que proporcionem melhorias tanto para o ambiente físico, como para os agentes deste ambiente, sem que altere o cotidiano e as vivências desses últimos. 


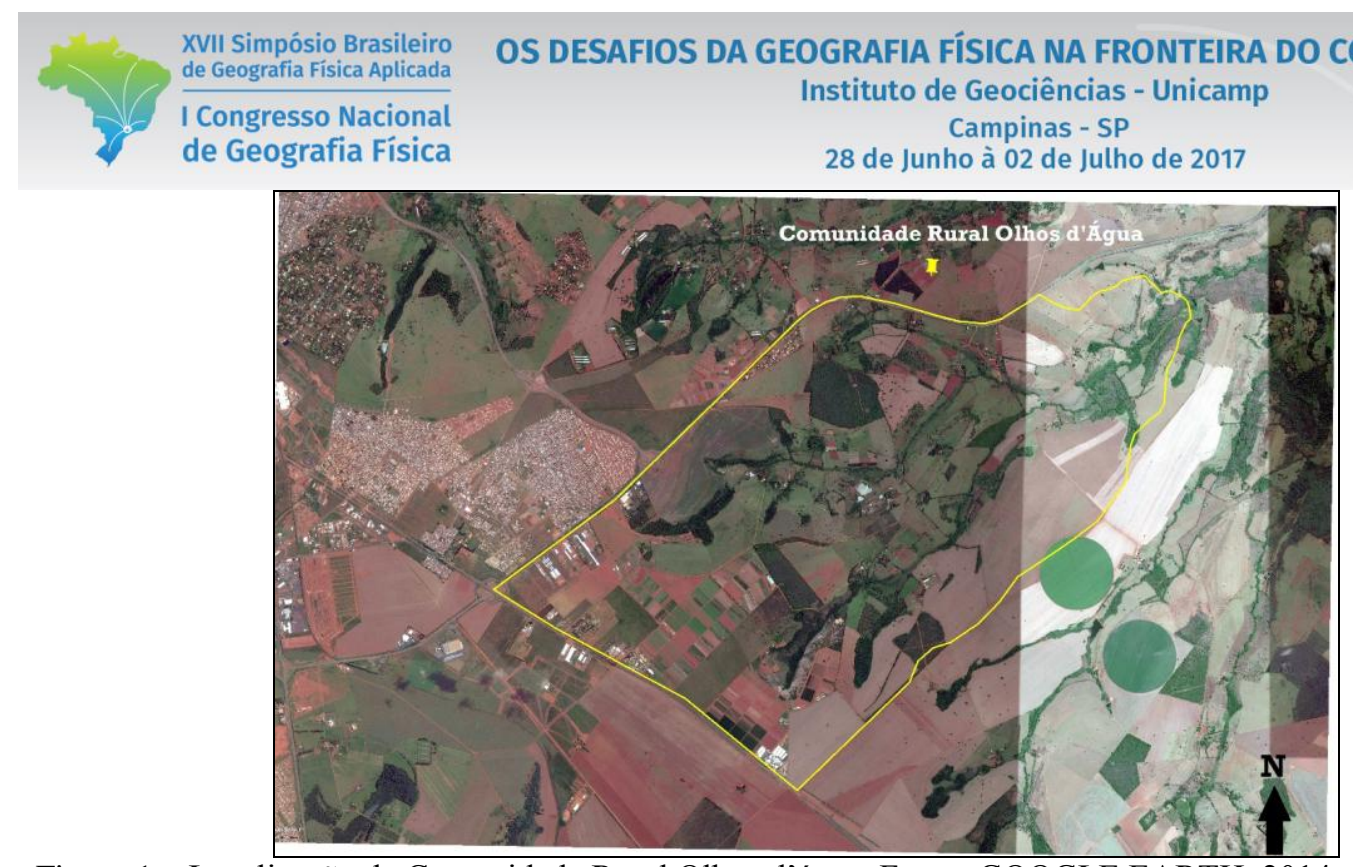

Figura 1 - Localização da Comunidade Rural Olhos d'água. Fonte: GOOGLE EARTH, 2014; Organizado por: BORGES, F.O.; 2015

Se compreendido que a análise do rural perpassa o entendimento do espaço "como algo dinâmico e mutável, reflexo e condição da/para a ação dos seres humanos, como espaço vivido e, por isso mesmo, 'representável', algo passível de 'apropriação"' (SERPA, 2006, p. 15), e que sofre influência/imposição do momento histórico, destaca-se que os sujeitos camponeses são passíveis de investigações significativas para análises de impacto socioambiental.

A agricultura camponesa é praticada por diversos sujeitos, dentre estes, os pequenos produtores rurais, considerados pela legislação como aqueles que residem na zona rural, têm posse de área menor que 50 (cinquenta) hectares cultivados com o trabalho pessoal e de sua família, onde a ajuda eventual de terceiros é admitida e a renda bruta proveniente de atividades agrícolas, pecuárias, silviculturais ou do extrativismo rural deve ser no mínimo de $80 \%$ (oitenta por cento) da renda total.

A Comunidade Rural Olhos D'água merece destaque em decorrência de aspectos marcantes na paisagem que refletem na produção camponesa, também por ser uma comunidade tradicional do município. Está localizada na porção nordeste de Uberlândia-MG, sua extensão vai desde a BR 365, Km 607, até o limite do município no Rio Araguari, caracteriza-se pela existência de muitas nascentes, áreas úmidas e córregos. Essa área possui predomínio de terras de boa qualidade utilizadas tradicionalmente para o cultivo de alimentos.

A produção ocorre principalmente em pequenas propriedades onde os sujeitos do/no campo utilizam das condições naturais e de práticas socioprodutivas derivadas dos saberes campesinos para continuarem produzindo no contexto agrícola contemporâneo. Nos trabalhos de campo na Comunidade Olhos D’Água foi possível observar que esse comportamento se faz presente e nutre a continuidade produtiva. 
Características naturais, como a forma de relevo e a hidrografia, são fundamentais para a continuidade da produção, pois nas pequenas propriedades da comunidade a agricultura se desenvolve com baixo uso de tecnologia e há diversificação dos cultivos que, em muitos casos, atrela os ciclos produtivos com os ciclos da natureza. A baixa inserção tecnológica repercute uma situação em que o cotidiano, marcado por incertezas, potencializa as dificuldades da vida no campo.

Ao pensar sobre os homens que vivem no/do lugar em estudo, foi possível efetivar observações coerentes com o modo como compreendem sua inserção no mundo. Por estabelecerem elos entre os aspectos produtivos, culturais e sociais do seu viver, constroem existências densas de significações.

Nota-se que transbordam a simplicidade de uma análise pautada pela sua condição de simples homens/mulheres trabalhadores (as). Elementos fundamentais de suas capacidades de produção do existir, como forças que dinamizam e reformam os meios de vida, os ciclos são parte integral das relações. As condições propiciadas pelos ciclos da natureza proporcionam a permanência dos sujeitos no lugar.

Por meio das mediações, entendiam (em) esse mundo que os cerca de pose a cunhar características que pudessem permitir a conservação do local. Lócus entendido na vivência dos camponeses no lugar, a qual é mediada por diversas interpretações e representações. De acordo com Kinn,

As interpretações camponesas no espaço vivido, sobre o plano da produção e da vida, são concebidas a partir de uma lógica pautada na manutenção da propriedade e na satisfação das necessidades sociais da família. [...] as relações de pertencimento, de identidade e enraizamento, o domínio de técnicas e de saberes, as histórias de vida propiciaram fundamentos para esses camponeses continuarem existindo, vivendo e lutando (KINN, 2010, p.101).

Por meio do trabalho com a terra, desenvolvem usos e apropriações do lugar que complementam sua existência e as propriedades de seu "ser". Aproximando de Debord, evidencia-se que "a apropriação pelo homem de sua própria natureza é também sua apropriação do desenrolar do universo" (DEBORD, 1997, p.87), ou seja, por meio das relações produtivas, também se produzem enquanto sujeitos.

Como pequenos produtores, desenvolveram vínculos com o meio em que estão envolvidos. Entendido "por aquilo que ele é no lugar em que vive, por aquilo que menciona, representa, por como age, reage, cria e (re)inventa, reinventando-se socialmente em situações reais e concretas" (KINN, 2010, p. 19), permanece mesmo perante as muitas dificuldades criadas pela instituição da propriedade capitalista. Esse elemento é reforçado por Woortmaan, que discorre que "Vê-se a terra, não como natureza sobre a qual se projeta o trabalho de um grupo doméstico, mas como patrimônio da família, sobre a qual se faz o trabalho que constrói a família enquanto valor.” (WOORTMANN, 1990, p.12) 
$\mathrm{Na}$ arquitetura de seus modos de vida (que são divergentes à lógica da mercadoria), como possibilidade de enfrentamento de uma realidade densa e complexa, muitas vezes para além do controle, desenvolveram estratégias de enfretamento. Em seu vir-a-ser, a comunidade, como constructo cultural e político, assume a característica de nos "proteger" através da coletividade. Como aponta Tuan, a cultura "enables us to forget the menacing Other -weather, for instance- by constructing a house. But its most basic contribution to forgetfulness, to an individual's sense of ease, lies in the construction of a 'we'. 'I' may be feeble, but 'we' are strong”' (TUAN, 1998, p.82).

A contribuição do autor se faz pertinente ao caso em estudo por mostrar a possibilidade de entender que as relações que um grupo tece com o espaço em que estão contextualmente inseridos fundam-se em suas necessidades. Pela poiésis da coletividade desvelaram importantes subterfúgios às dificuldades de enfrentamento da realidade geográfica.

No grupo, as relações campesinas vão além do âmbito econômico, consideram-se as pessoas que estão envolvidas numa confiança na "palavra" do outro, envolvem mais os sujeitos pertencentes à coletividade que o dinheiro em si. Tal como Woortman (1990) aponta, na lógica do camponês a reciprocidade é priorizada ante ao "negócio". Como ressalta Brandão (1993), seus relacionamentos tem um componente 'mágico' fundante que é a priorização da comunidade ante ao indivíduo.

Diz que "o negócio é percebido como negação da moralidade, pois ele significa ganhar às custas do trabalho alheio" (WOORTMAN, 1990, p. 38), a retratar nexos residuais de associações com a religiosidade católica. As relações, por esse caráter, têm mediações nos "favores". A ajuda de hoje pode transcender em um bom casamento para o filho ou em doação de trabalho na próxima colheita, visto que ambos elementos são baluartes das relações no sítio (WOORTMAN; WOORTMANN, 1992).

Simmel, em estudo sobre a sociabilidade e individualidade, desvela que acima de todo seu conteúdo "especial", "all these associations are accompanied by a feeling for, by a satisfaction in, the very fact that one is associated with others and that the solitariness of the individual is resolved into togetherness, a union with others" (SIMMEL, 1971, p.128). Para além das necessidades, há desejo do indivíduo em se sentir parte de algo maior. Como continuam com certo sentimento de ausência de auxílio do Estado, os produtores campesinos propiciam suas próprias possibilidades de reprodução da existência no lugar.

Acordando com a proposição de que "tudo nos reenvia às relações orgânicas entre o sujeito e o espaço, a esse poder do sujeito sobre seu mundo que é a origem do espaço." (MERLEAU-PONTY, 2001, p.338), nota-se uma necessidade intrínseca de evidenciar como lugar, na condição de espaço, é poiésis. Criação coletiva e individual que tem gênese na reprodução de um viver. 
Ora, se considerar, de maneira precavida, que, como argumentam Scannel e Gifford, "bonding is central to the human experience. We necessarily form meaningful connections with particular people, groups, objects and places" (2014, p.23), vincular-se é uma ação que parte tanto do indivíduo como do grupo, é relacional.

De acordo com Santos e Kinn, "entre pessoas que mantêm identidades com um mesmo lugar, o pertencimento é uma construção social que implica relações que estabelecem e mantêm vínculos com o lugar." (2009, pp. 63-64). Entre as concepções dos quatro autores previamente citados, percebe-se que há um fio condutor para a construção do lugar-coletivo que está implicado na reprodução de uma existência dotada de intencionalidades densas e complexas.

Dialogicamente, os vínculos com o lugar são multidimensionais, de escalaridade variada, até porque, como nos ajuda a refletir Seamon, "place attachment is part of a broader lived synergy in which the various human and environmental dimensions of place reciprocally impel and sustain each other" (2014, p.12). As internalidades e externalidades da existência propiciam dinamismo para viver o espaço enquanto uma virtualidade do uso no devir da apropriação. Na situação em destaque, os sujeitos desvelam um modo de viver no lugar em que há necessidade de constante reate de laços comunais para estabelecer permanências.

Essas concepções, por vezes próximas, permitem transcender um entendimento de lugar que venha a ser apenas conectada aos sentidos afetivos estabelecidos na relação homem-meio. Partindo do pressuposto de Karjalainen, de que "lugares são as partes da realidade espacial que foram reclamadas pelas intenções humanas" (KARJALAINEN, 2012, p.7), pensa-se que é fundamental ponderar os vínculos com valências tanto positivas como negativas.

Existir no lugar é uma situação contextual e relacional que, ao mesmo tempo, liberta de um estado de permanente ansiedade (TUAN, 2005), como prende a determinadas situacionalidades (BOURDIN, 2001). No caso em estudo, nota-se que alguns dos sujeitos usam a comunidade como "escape" para as dificuldades que clivam seu cotidiano, mesmo que isso retire parte de suas individualidades.

Essa situação da comunidade em lócus toma novas escalas. Conforme vários deles passaram a efetivar transformações nas técnicas de manejo, seja por "força" da legislação ou por imposições capitalistas (ou ambas, entre outras), essa necessidade de se recorrer ao grupo passa a ser ressignificada. O transformar dessas práticas ocasionaria, teoricamente, em uma desfiguração de suas condições de camponeses, visto que passam a ser subordinados ao nexo da mercadoria. 


\section{OS DESAFIOS DA GEOGRAFIA FÍSICA NA FRONTEIRA DO CONHECIMENTO \\ Instituto de Geociências - Unicamp \\ Campinas - SP \\ 28 de Junho à 02 de Julho de 2017}

Contudo, essa representação não deixa de existir. Para o Estado, se travestem, assumem nomes e formas que visam favorecer sua estância. O "ser" campesino deixa de ser a identidade/representação aparente desses homens/mulheres, pela denominação de produtores familiares têm acesso facilitado às técnicas e aos financiamentos.

$\mathrm{Na}$ lógica capitalista e do planejamento territorial, o conselho comunitário é uma conquista da comunidade, que tem algumas de suas demandas ouvidas e providências tomadas. Na reinvenção evidenciada neste estudo, há uma apropriação desta ferramenta de planejamento pela lógica campesina, tomada na sua condição de resíduo potencializador.

Assumindo caracteres virtualizantes, as características desse modo de viver no e do lugar os tornam sujeitos transcendentais, capazes de entender os contextos em que estão inseridos e reexistirem. Mais que uma resistência às imposições, é modo de continuidade da reprodução de algo que, pela ordem "racional", deveria ter sido abandonado.

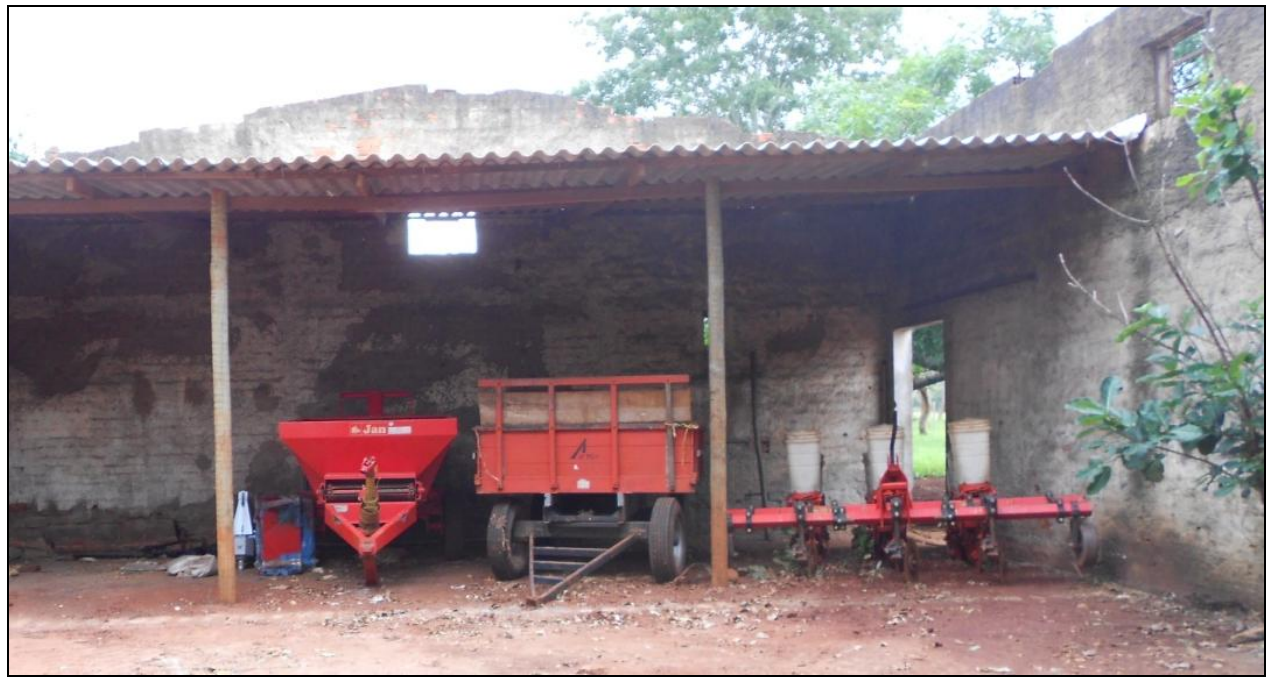

Foto 1 - Equipamentos de uso comum, disponíveis para uso da comunidade, o usuário arca com uma "diária", para subsidiar a manutenção. Fonte: Trabalhos de campo realizados pelos autores, 2015.

Pelo uso de maquinário partilhado, por exemplo, constroem, a partir de lógicas camponesas, meios para continuar a viver do lugar. Na reciprocidade comunitária, conseguem efetivar certa medida de controle dos usos destas potencialidades, maximizando as capacidades do mundo em que realizam seus cotidianos.

Nas novas condições, é interessante evidenciar que o caráter familiar do modo de produção permanece. Para trabalhar na lavoura, os filhos adultos que hoje moram na cidade vão diariamente trabalhar na propriedade dos pais. Por vezes as mulheres e os filhos trabalham no ambiente urbano, mas continuam a auxiliar em momentos de colheita mais intensa. 
Nessa comunidade rural é possível encontrar fazendas mais antigas que se dedicam à criação de gado, frangos e porcos. Ainda há marcante presença de pequenos produtores rurais que praticam, principalmente, a olericultura e fruticultura cuja produção é destinada ao mercado consumidor de Uberlândia.

Os moradores, em alguns casos, estabelecem relações de escambo (fundamentalmente pré-capitalista) nas quais determinados produtos não se tornam exatamente mercadorias, mas elementos de trocas. Essas são mediadas por uma lógica que vê na sociabilidade a fundamentação de particular sentido e valor humano, em que "a reciprocidade é o contrato social do camponês hierárquico no interior do todo que é a comunidade" (WOORTMANN, 1990, p.67). Em outros momentos, parte do resultado das colheitas é doado para a capela da comunidade, principalmente com a funcionalidade de auxiliar nas festividades, elemento significativo de suas identidades.

Isso é recorrente nas folias de reis, comuns na área em estudo. Contudo, a doação não é característica durante as cavalgadas organizadas pelos moradores, nelas há arrecadação financeira visando um almoço comum entre os "cavaleiros". Mesmo assim, ambas são oportunidades de reunião nas quais atos de reciprocidade tendem a aflorar. Ao prosearem, dividem experiências de vida e lida que virtualizam a vida do lugar, tanto em sua escala coletiva quanto individual. As reuniões não são apenas dos homens/mulheres, mas de seus elementos de vínculo ao lugar que, juntos, conseguem materializar reatividades coesivas que partem da lógica campesina.

O lugar, no caso em estudo, se torna um entre-espaço de relações, nas quais os sujeitos podem potencializar suas existências. No lugar, os enraizamentos e elos são elementos que trazem grandes transformações para os camponeses travestidos de produtores familiares. Cada qual com seu fim têm no coletivo o agrupamento de sentido (e, talvez, de poder) necessário para a continuidade dos vínculos, considerando-os em seus devires.

\subsection{Impactos Socioambientais}

A bacia hidrográfica do córrego Olhos D’água possui grande importância como manancial de água utilizado para irrigação em pequenas propriedades rurais, sendo a maior parte da disponibilidade hídrica direcionada para a horticultura familiar (OLIVEIRA, 2012). Nesse sentido, a região que abrange o conjunto de bacias do córrego Olhos D'água, Três Marcos e Marimbondo constituem um importante cinturão verde responsável pela maior parte de produtos de horticultura que abastece a cidade de Uberlândia. 
No entanto, a disponibilidade hídrica do córrego Olhos D'água encontra-se diretamente relacionada à vazão do córrego Três Marcos, já que a modalidade de agricultura praticada no primeiro córrego é feita por meio de uma transposição realizada por um canal superficial que desvia parte da água do córrego Três Marcos. Nesse sentido, a disponibilidade hídrica do córrego Três Marcos possui grande importância para a manutenção da vazão mínima para a atividade agrícola dos minifúndios, encontrando-se em processo de comprometimento pela intensa ocupação urbana nas áreas de recarga da nascente deste córrego. Além disso, à medida que a área urbana se amplia, os impactos sobre os diferentes componentes da paisagem também crescem na mesma proporção, à exemplo do lançamento de águas pluviais não infiltradas através do solo diretamente nos cursos d'água (OLIVEIRA, 2012).

Dessa forma, mostra-se importante a análise dos processos de impermeabilização do solo na área de contribuição da bacia estudada que, segundo Oliveira (2012) pode promover em curto prazo na escassez de água via a redução da vazão e/ou contaminação. Apesar de tratar-se de ocupação por minifúndios, a disponibilidade hídrica (seja qualitativa ou quantitativa) da bacia do córrego Olhos D’Água encontra-se comprometida por dois principais aspectos: o primeiro de caráter interno, sendo a própria utilização irregular dos pequenos produtores de horticultura, seja na captação ou no lançamento de efluentes contaminados pelo uso humano ou pela presença de químicos provenientes das culturas; e o segundo aspecto de caráter externo, sendo a alteração qualitativa/quantitativa da água através do desvio (localmente chamado de rego de água) proveniente dos impactos socioambientais que ocorrem na bacia do córrego Três Marcos.

Pode-se inferir, portanto, que o planejamento ambiental na região da bacia do córrego Olhos D’Água mostra-se de suma importância para evitar ou remediar as ações antrópicas sobre o meio ambiente, além de proporcionar o mantenimento das atividades agrícolas de caráter familiar que dependem diretamente dos recursos hídricos para irrigação das culturas. Nesse sentido, a preocupação do planejamento ambiental nessa área possui caráter de preocupação ambiental, no sentido da preservação e melhora dos aspectos qualitativos e quantitativos, além da preocupação social, política e econômica para as atividades de horticultura presentes na região.

\subsection{A Educação Ambiental como "solução"}

O córrego Olhos D’Água tem sua ocupação relacionada com a do Triângulo Mineiro. Em 1827 que os irmãos Carrijo tomam posse das terras e começam o desmatamento para o plantio, criação de gado, e desenvolvimento, ampliam as trilhas para as estradas de rodagem do trânsito comercial. 
As terras apresentavam condicionantes naturais que propiciaram sua ocupação e plantios de subsistência.

Por conta das atividades exercidas nesta área, faz-se necessário grande utilização de insumos químicos e agrotóxicos nas plantações, o que, por consequência, contamina a água do córrego e o solo. Observa-se que os regos d'água que foram construídos para abastecer de forma coletiva as propriedades rurais desta bacia, sendo esta a principal fonte de abastecimento d'água.

Visto isso, é importante que essas áreas sejam protegidas e conservadas, buscando melhorar a segurança alimentar para a cidade e principalmente para a comunidade Olhos D’Água. Pensando na conservação destas áreas, foram desenvolvidos projetos de educação ambiental com a população residente. De acordo com Quintas (2008, p. 35):

a Educação Ambiental deve proporcionar as condições para o desenvolvimento das capacidades necessárias; para que grupos sociais, em diferentes contextos socioambientais do país, intervenham, de modo qualificado tanto na gestão do uso dos recursos ambientais quanto na concepção e aplicação de decisões que afetam a qualidade do ambiente, seja físico-natural ou construído, ou seja, educação ambiental como instrumento de participação e controle social na gestão ambiental pública.

É um processo de aprendizagem que exige tanto individualmente e politicamente, quanto de grupos coletivos a responsabilidade de pensar o espaço estudado de forma sustentável, crítica, levando em consideração atitudes e valores que visam sempre a preservação do meio ambiente.

Contudo, não devemos pensar em educação ambiental apenas como preservação da natureza, mas sim, pensar uma construção da sociedade sustentável ecologicamente equilibradas e socialmente justas. Isso remete a ideia de melhor qualidade de vida das pessoas que vivem neste ambiente, pois se preocupa com a construção das relações sociais mais justas e igualitárias.

Seguindo este contexto, a Universidade Federal de Uberlândia em conjunto com a Prefeitura de Uberlândia e a Comunidade Olhos D’Água criaram projetos que conscientizassem as pessoas e permitissem melhor acesso ao conhecimento em relação ao assunto tratado, com o objetivo de mudanças do comportamento destas pessoas, por meio da educação crítica e transformadora.

Foram realizadas palestras, como por exemplo, a de manejo e conservação do solo, que visavam ensinar técnicas que tenham menor impacto sobre o solo no manejo para a produção de alimentos; Uso da água, com fins de conscientizar a população acerca da melhor utilização deste recurso para que não haja desperdício em seu consumo doméstico ou nas plantações.

Oficinas foram feitas com temas importantes como: "Agricultura familiar", que é uma atividade rural tão importante nesta área; "Sustentabilidade", sendo este um dos principais focos do projeto; "Outorga", foram concedidas outorgas, assegurando a comunidade o direito de utilização dos recursos hídricos; 
“Análise do uso da água”, bastante importante, pois, esta água é utilizada para o consumo e é importante também para ter um melhor acompanhamento dos resultados das mudanças comportamentais; "Coleta seletiva do lixo", que depois vão para o processo de reciclagem; entre outras oficinas que oferecem maior conhecimento a população.

Além disto, também foram orientados na plantação de banana, chuchu, limão, como mostrado na imagem abaixo:

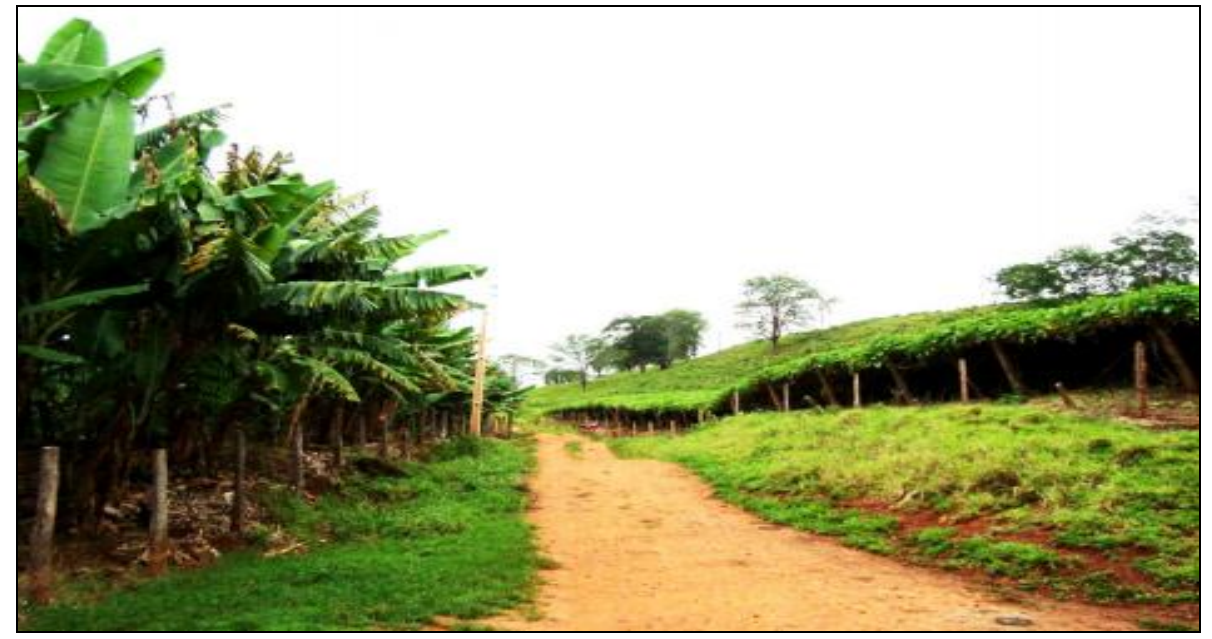

Foto 2: Plantação de banana (à esquerda) e chuchu (à direita). Fonte: Oliveira, 2012.

A verba utilizada para os projetos nesta comunidade vem uma parte da prefeitura e a outra é arrecadada por meio de gincanas, festas culturais e outras atividades. Todo mês há reuniões mensais com o conselho que determina as atividades que serão realizadas no decorrer de seus dias.

Todos esses projetos são fundamentais para a melhor gestão dos recursos, evitando que haja degradação deste ambiente. Trabalhando em conjunto, contribui diretamente não só para a preservação ambiental, mas para a preservação do patrimônio, da tradição que na comunidade e, principalmente, a reprodução das relações sociais.

\section{Apontamentos (encenando) conclusões}

Ter uma bacia hidrográfica como unidade de planejamento é essencial para a distribuição de políticas públicas e planos de gestão por ser um recorte menor, com particularidades reduzidas, facilitando suas ações. Porém, é importante destacar que ao utilizar uma bacia hidrográfica como unidade de gestão, devese levar em consideração todos os seus fatores, sejam esses físico-naturais ou antrópicos, para que as aplicações não atinjam apenas uma pequena minoria, além de sua região de influência. 


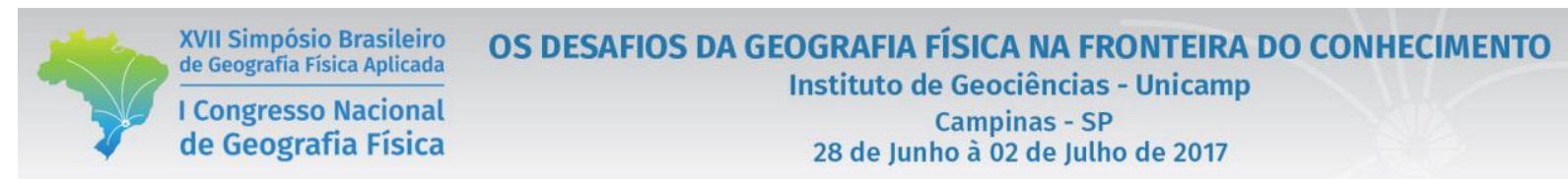

A partir de trabalhos de campo, que permitiram a interação com os sujeitos e registros fotográficos do lugar, foi possível identificar os problemas socioambientais envolvidos na área de estudo e as formas que os sujeitos pertencentes ao lugar usam para reverter tais impactos.

Com o que foi exposto no trabalho, foi possível confirmar a importância dos aspectos socioambientais em um recorte de bacia hidrográfica, visto que os sujeitos usufruem do ambiente e contam sua história e, a partir disso, torna-se mais aplicável as ações de planejamento, visando conservar todos os atributos envolvidos no recorte territorial.

No caso em estudo, foi preciso aproximações entre a Universidade e a Comunidade Rural para que houvesse atenção maior para aqueles envolvidos na área. Utilizando das estratégias mencionadas, com a aplicação pesquisas e promoção de atividades e oficinas educativas, auxiliou-se na preservação da água e dos recursos naturais ali presentes. Por meio disso, percebe-se que não existe planejamento ambiental sem o envolvimento dos sujeitos, uma vez que estes são os principais agentes do recorte espacial.

\section{Bibliografia}

SANTOS, R. F. dos. Área, escala e tempo: paradigmas do planejamento. In: Planejamento Ambiental: teoria e prática. São Paulo: Oficina de Textos, 2004, p. 39-70.

SCANNEL, L.; GIFFORD, R. Comparing the theories of interpersonal and place attachment. In: MANZO, L. C. (Org.); DEVINE-WRIGHT, P. (Org.) Place Attachment: advances in theory, methods and applications. Abingdon: Routledge, 2014, pp. 23-36.

BRANDÃO C. R. O desencanto do outro: Mistério, Magia e Religião nos estudos do mundo rural no Brasil. Anuário Antropológico, UNB: Brasília, p.9-30, v.91, n.1, 1993.

OLIVEIRA, H. L. de P. R. Análise da influência dos fatores naturais e antrópicos na disponibilidade hídrica no alto curso do córrego Três Marcos: Subsídios para a gestão integrada das águas superficiais e subterrâneas. 2012. 174 f. Dissertação (Mestrado) - Curso de Geografia, Universidade Federal de Uberlândia, Uberlândia, 2012.

QUINTAS, J. S. A educação no processo de gestão ambiental. In: futuro: Educação Ambiental no Brasil. Rio de Janeiro: Tv Escola, 2008. p. 30-38.

Ministério da Educação, Salto para o

SANTOS, R. J.; KINN, M. G. Festas: Tradições reinventadas nos espaços rurais dos cerrados de Minas Gerais. Espaço e Cultura. UERJ: Rio de Janeiro, p. 58-71. n. 26, jul./dez. 2009.

TUAN, Y. Espaço e lugar: a perspectiva da experiência. Londrina: EdUel, 2013.

BOURDIN, A. A questão local. Rio de Janeiro: DP\&A, 2001.

TUAN, Y. Paisagens do medo. São Paulo: Editora UNESP, 2005.

KARJALAINEN, P. T. Place in Urwind: A humanist geography view. Geograficidade. v. 2, n. 2, Inverno 2012. p.422.

MERLEAU-PONTY, M. Fenomenologia da percepção. São Paulo: Martins Fontes, 2011.

SEAMON, D. Place attachment and phenomenology: The synergistic dynamism of place. In: MANZO, L. C. (Org.); DEVINE-WRIGHT, P. (Org.) Place Attachment: advances in theory, methods and applications. Abingdon: Routledge, 2014, pp. 11-22. 
TUAN, Y. Escapism. Baltimore: The Johns Hopkins University Press, 1998.

WOORTMANN, K. "Com Parente não se neguceia": Campesinato como ordem moral. Anuário Antropológico, UNB: Brasília, p.11-73, v. 87, n. 1, 1990.

SIMMEL, G. On individuality and social forms. Chicago: The University of Chicago Press, 1971.

DEBORD, G. A sociedade do espetáculo. Rio de Janeiro: contraponto, 1997. 